\title{
PARTICIPAÇÃO DOS MASTÓCITOS NO REPARO TECIDUALE EM LESÕES INFLAMATÓRIAS BUCAIS - UMA REVISÃO DE LITERATURA
}

\author{
Kariza Vargens Diniz Correia Mestre em Estomatologia pela Escola \\ Bahiana de Medicina e Saúde Pública. \\ Professora do curso de Odontologia \\ da Faculdade Independente do \\ Nordeste.
}

\author{
Alena Ribeiro Alves Peixoto Medrado Doutora em Patologia Humana pela \\ Universidade Federal da Bahia. \\ Professora Adjunto do curso de \\ Odontologia da EscolaBahiana de \\ Medicina e Saúde Pública.
}

\begin{abstract}
Resumo
Os mastócitos são células móveis que contêm grânulos, derivados da medula óssea e estão amplamente distribuídos nos tecidos conjuntivos participando ativamente das respostas imunológicas. O envolvimento destas células tem sido demonstrado nos processos de inflamação, angiogênese e fibrose, nos quais atuam por meio de seus produtos de secreção. O objetivo dessa revisão de literatura é abordar o envolvimento dos mastócitos nos fenômenos biológicos que integram o contexto do reparo tecidual, a exemplo da vasodilatação, angiogênese e fibrose, com ênfase na caracterização do perfil destas células em lesões inflamatórias bucais. Apesar de poucos estudos contemplarem a participação dos mastócitos em lesões orais, alguns trabalhos têm demonstrado que tais células estão envolvidas na patogênese de lesões periapicais, ulcerações aftosas recorrentes, cistos odontogênicos, entre outros. O avanço do conhecimento acerca do mecanismo de ação dessas células tem estimulado o desenvolvimento de terapias cujo alvo principal é a regulação dos mediadores químicos liberados pelos mastócitos. Logo, espera-se que através de novas investigações, as desordens inflamatórias da cavidade oral e outras patologias que exibam mastócitos em seu interstício, possam ser melhor compreendidas, em especial no que diz respeito ao papel biológico que estas células poderiam exercer nestas lesões.
\end{abstract}

Palavras-chave: Mastócitos; Inflamação; Moduladores da Angiogênese.

\section{INVOLVEMENT OF MAST CELLS IN TISSUE REPAIR AND IN INFLAMMATORY ORAL LESIONS - A LITERATURE REVIEW}

\begin{abstract}
Mast cells (MCs) are mobile cells that contain granules, derived from bone marrow and are widely distributed in tissues actively participating in immune responses. The involvement of these cells has been demonstrated in the inflammation, fibrosis and angiogenesis, in which they act through their secretory products. The purpose of this literature review is to address the involvement of MCs in biological phenomena that comprise the context of tissue repair, such as vasodilation, angiogenesis and fibrosis, with emphasis on the characterization of the profile of these cells in inflammatory lesions mouth. Although few studies contemplate the participation of MCs in oral lesions, some others have shown that these cells are involved in the pathogenesis of periapical lesions, aphthous ulcers, odontogenic cysts, among others. The advancement of knowledge about the mechanism of action of these cells, has stimulated the development of therapies whose chief aim is the regulation of chemical mediators released by mast cells. Therefore, it is hoped that through further investigations, inflammatory disorders of the oral cavity and other conditions that display interstitial MCs, might be better understood, mainly concern to MCs biological behavior.
\end{abstract}

Keywords: Mast Cell; Inflammation; Angiogenesis modulators. 


\section{INTRODUÇÃO}

Os mastócitos (MCs) são células grandes derivadas da medula óssea que apresentam um grande número de grânulos citoplasmáticos contendo em seu interior substâncias como histamina, heparina e proteases neutras e exercem uma ação biológica decisiva nos mecanismos de lesão tecidual e defesa imunológica. ${ }^{(1,2)}$ Embora sejam provenientes de células sanguíneas indiferenciadas, completam a sua maturação no tecido conjuntivo distribuído pelo organismo e em especial, nas mucosas. São encontrados em áreas perivasculares, bem como no sistema nervoso periférico e central. ${ }^{(3)}$ Galli, $^{(4,5,6)}$ relata a participação dos MCs na imunidade inata contra a infecção bacteriana e ainda a influência destas células em muitas outras respostas biológicas, incluindo a remodelação do tecido e angiogênese.

Tem sido relatada a participação de MCs em reações de hipersensibilidade, alterações vasculares presentes no processo inflamatório a exemplo da vasodilatação e angiogênese, formação do tecido de granulação e biossíntese do colágeno durante a cicatrização de ferimentos, entre outros processos patológicos. ${ }^{(1,2)}$ A participação dessas células em reações anafiláticas relacionadas a alimentos, picadas de insetos ou drogas, faz com que elas degranulem e assim liberem mediadores como a histamina e os produtos da oxidação do ácido aracdônico. ${ }^{(3)}$

Os mastócitos produzem uma ampla variedade de mediadores químicos, os quais acham-se relacionados com a proliferação vascular e vasodilatação e são também capazes de modular a inflamação. ${ }^{(2,7)}$ Além disso, a interação fibroblasto/mastócito descrita na literatura possibilita a estas células desempenharem um papel-chave na deposição de colágeno no interstício, em particular, nas lesões inflamatórias da mucosa oral e em outras patologias de natureza inflamatória. ${ }^{(1)}$ Corroborando esses dados descritos na literatura, Li e Baek ${ }^{(8)}$ demonstraram que os MCs podem afetar o comportamento funcional dos fibroblastos e, consequentemente, o processo de fibrose pela exocitose de mediadores pré-formados como as citocinas fibrogênicas a exemplo do fator de crescimento derivado de plaquetas (PDGF), fator de crescimento transformador beta (TGFß) e fator de crescimento fibroblástico básico (bFGF).

Há um papel fundamental dos MCs no desenvolvimento da inflamação na mucosa oral, tanto no início, com eventos vaso-indutivos, quanto na transição da inflamação aguda para crônica. ${ }^{(9)}$ Murataet al. ${ }^{(10)}$ verificaram um aumento do número destas células no estágio inicial da epulis e produção de bFGF por tais elementos celulares durante o desenvolvimento 
da lesão. O melhor desempenho dos MCs durante a neovascularização do tecido de granulação foi verificado, mas houve uma diminuição da quantidade de MCs quando o processo de fibrose estava acelerado e neste estágio eles estavam localizados somente na periferia do tecido fibroso.

A pluralidade de funções dos MCs, tais como as ações biológicas deflagradas pela liberação da quimase e da triptase que representam enzimas participantes da destruição da membrana basal ${ }^{(9)}$ e ao mesmo tempo, o seu papel protetor e anti-inflamatório na imunidade inata e adaptativa, ${ }^{(11)}$ desperta para o fato de que o conhecimento sobre essa célula polêmica precisa ser ampliado.

O objetivo dessa revisão de literatura é abordar o envolvimento dos MCs nos fenômenos biológicos que integram o contexto do reparo tecidual, a exemplo da vasodilatação, angiogênese e fibrose, com ênfase na caracterização do perfil destas células em lesões inflamatórias bucais.

\section{REVISÃO DE LITERATURA}

\section{Mediadores Químicos dos Mastócitos e Ações Biológicas}

A diversidade de papéis exercidos pelos MCs se dá devido à sua capacidade de liberação de mediadores químicos. Essas substâncias podem ser agrupadas em três classes distintas como os mediadores pré-formados associados aos grânulos, os mediadores derivados de lipídios e as citocinas. ${ }^{(9,12,13)}$

A histamina, a única amina vasoativa armazenada nos grânulos de mastócitos humanos, exerce um efeito vasodilatador predominantemente sobre os vasos sanguíneos finos, resultando em aumento da permeabilidade vascular, maior afluxo sanguíneo na microcirculação, queda da resistência periférica total e redução da pressão sanguínea. Adicionalmente, armazenados nos grânulos podem ser encontrados proteoglicanos a exemplo da heparina e proteases, como a quimase e a triptase. ${ }^{(14,15)}$ A família das interleucinas é vasta em quantidade e em funções (IL-3, -4, -5, -6, -8, -10, -13 e -16), inclusive na influência na maturação dos próprios MCs. ${ }^{(15)} \mathrm{O}$ Quadro 1 ilustra a grande diversidade de mediadores químicos sintetizados pelos MCs e suas respectivas ações biológicas.

Adicionalmente, Santos et al. ${ }^{(16)}$ salientaram a relevância do desempenho dos mastócitos descrevendo o seu papel protetor na imunidade inata, e o seu papel pró- 
inflamatório. Estas ações biológicas, protetora e pró-inflamatória, parecem ser contraditórias. No entanto, esta aparente contradição é um importante fator a ser levado em conta, pois se constitui a principal preocupação de pesquisadores que buscam uma adequada abordagem terapêutica das lesões teciduais nas quais estas células se fazem presentes.

Por conta dos eventos da cascata da angiogênese dependerem de processos complexos que incluem interações célula-célula, várias vias de sinalização intracelular e microambiente extracelular apropriado, ainda é necessário identificar as circunstâncias nas quais os MCs representam uma fonte de fatores angiogênicos in vivo. ${ }^{(7)}$ Além de produzir e lançar esses fatores, os MCs são recrutados aos sítios de angiogênese por meio de alguns deles como o fator de crescimento endotelial vascular (VEGF), bFGF e outros. ${ }^{(17)}$

Quadro 1 - Mediadores Químicos Encontrados nos Grânulos Citoplasmáticos dos Mastócitos

\begin{tabular}{|llll|}
\hline \multirow{2}{*}{$\begin{array}{l}\text { Mediadores } \\
\text { pré-formados }\end{array}$} & Aminas & Histamina & $\begin{array}{l}\text { Aumento da permeabilidade; } \\
\text { estímulo à contração das células da } \\
\text { musculatura lisa }\end{array}$ \\
\cline { 2 - 4 } & Enzimas & Triptase; & $\begin{array}{l}\text { Degradação da estrutura microbiana; } \\
\text { dano/remodelação tecidual } \\
\text { Mitógenas para fibroblastos; } \\
\text { quimiotáticas para macrófagos }\end{array}$ \\
\hline $\begin{array}{l}\text { Mediadores } \\
\text { produzidos na } \\
\text { ativação }\end{array}$ & Lipídicos & Prostaglandinas & $\begin{array}{l}\text { Vasodilatação, broncoconstrição, } \\
\text { quimiotaxia de neutrófilos }\end{array}$ \\
\cline { 2 - 4 } & & Leucotrienos & $\begin{array}{l}\text { Broncoconstrição, secreção de muco, } \\
\text { aumento de permeabilidade vascular }\end{array}$ \\
\cline { 2 - 4 } & & $\begin{array}{l}\text { Fator ativador } \\
\text { de plaquetas }\end{array}$ & $\begin{array}{l}\text { Broncoconstrição, quimiotaxia e } \\
\text { ativação de leucócitos, aumento de } \\
\text { permeabilidade vascular }\end{array}$ \\
& Citocinas & IL-3 & Proliferação de mastócitos \\
\cline { 2 - 4 } & & TNF- $\alpha$ & Reação tardia/inflamação \\
\cline { 2 - 3 } & IL-4, IL-3 & Diferenciação de T 2 \\
\cline { 2 - 3 } & IL-5 & Ativação e produção de eosinófilos \\
\hline
\end{tabular}

Fonte: Adaptado de Abbas (2000) e Robbins (2005).

Mastócitos humanos expressam constitutivamente VEGF e bFGF,potentes fatores de crescimento angiogênico, os quais são localizado em 97\% dos mastócitos triptase positivos no tecido de pulmão humano fibrótico. ${ }^{(18)}$ A triptase de MCs é um mitógeno tanto para células epiteliais, estimulando a produção de IL-8 e a expressão de molécula de adesão intercelular 1(ICAM-1), como para células endoteliais microvasculares, induzindo angiogênese e formação de capilares sanguineos. ${ }^{(19)}$ 
Ribattiet al. ${ }^{(20)}$ sugeriram que um número crescente de MCs podem ser recrutados e ativados por mais células malignas do plasma em mieloma múltiplo ativo, e que a angiogênese nesta fase da doença pode ser mediada, ao menos em parte, por fatores angiogênicos contidos nos seus grânulos de secreção.

Os MCs têm sido implicados em várias doenças que exibem concomitantemente o processo de neovascularização e fibrose. A íntima relação anatômica entre MCs e a vasculatura e o aumento da taxa de aparecimento dessas células durante o crescimento tumoral, cicatrização e inflamação, processos que são acompanhados pela neovascularização, ratificam essa associação.

Grützkauet al. ${ }^{(21)}$ verificaram que tanto MCshumanos normais, como osconstitutivamente presentes em leucemiasexpressam VEGFbioativos. Além disso, este estudocontribuiu paraacompreensãodopapel fisiológicodasisoformas de heparina eVEGF, através de dados coletados por meio das técnicas de reação em cadeia da polimerase (PCR), Western Blot e ELISA.

\section{Participação de Mastócitos na Fibrose}

Muitos estudos têm demonstrado a interação dos MCs com fibroblastos e sua contribuição para a síntese de colágeno em condições patológicas, a exemplo da esclerodermia, fibrose renal e cutânea. ${ }^{(14,15)}$ Adicionalmente, os MCs também são encontrados no contexto de várias doenças humanas, tais como a fibrose pulmonar, cirrose hepática e quelóide. Mediadores dos MCs são citados como mitogênicos e quimiotáticos para fibroblastos. É citado na literatura um possível papel dos MCs em síntese aumentada de colágeno e de fibrose na pele induzida por radioterapia. ${ }^{(1,22,23,24)}$

Roberts e Brenchley ${ }^{(15)}$ constataram que um aumento do número de MCs é uma característica constante da fibrose renal, independentemente da patologia subjacente. Além disso, verificaram que o número de MCs se correlaciona com o grau de fibrose intersticial. Os autores avaliaram transplantes renais rejeitados e biópsias de pacientes com nefropatias. Foi observada pequena quantidade ou ausência de MCs em rins normais e uma grande quantidade destas células em biópsias de pacientes com nefropatias, sugerindo um possível papel dessas células no processo fibrótico. Resultados inversos foram descritos por Miyazawa et al., ${ }^{(25)}$ os quais avaliaram o papel dos MCsnafibroserenalatravés da análiseexperimentalde 
doençaglomerular e constatatram que os MCs não desempenharam um papel importante na patogênese da fibrose intersticial em nefrose.

O processo fibrótico pesquisado em rins é caracterizado por um infiltrado inflamatório crônico e pela proliferação de miofibroblastos no interstício. Este processo é conduzido por uma rede de citocinas que inclui fatores de crescimento para miofibroblastos, tais como PDGF, bFGF. ${ }^{(15)}$

Os fibroblastos desenvolvem um importante papel na promoção do crescimento de alguns tipos de células cancerígenas e existem relatos na literatura que abordam a influência de mediadores dos MCs sobre estas células. Por exemplo, Samoszuket al. ${ }^{(26)}$ sugeriram que os MCs em regiões fibrosas de tumores produziriam heparina, a qual suprimiria o crescimento das célulastumorais através deum mecanismo indireto envolvendo fibroblastosadjacentes.

\section{Participação dos Mastócitos em Lesões Bucais}

Natahet al. ${ }^{(27)}$ encontraram MCs no infiltrado inflamatório de ulcerações aftosas recorrentes. Para os autores a presença de MCs na membrana basal dessas lesões não significa que estas células desenvolvam apenas um papel destrutivo. Os autores destacam, de forma semelhante a outros estudos já citados, que os MCs estariam envolvidos no processo de reparo final desse tipo de lesão.

Farahaniet al. ${ }^{(1)}$ analisando quatro lesões reativas orais (fibroma de irritação, hiperplasia fibrosa inflamatória, granuloma periférico de células gigantes e fibroma ossificante periférico) do arquivo do Departamento de Patologia da Faculdade de Odontologia, Iazd - Irã, pesquisaram mastócitos por meio da coloração azul de toluidina e o grau de inflamação por meio de coloração com hematoxilina-eosina e encontraram um número de MCs aumentado nessas lesões em comparação ao tecido gengival normal, obtido em cirurgias de terceiro molar impactado. Além disso, foi observada uma significativa correlação entre o grau de inflamação e a presença destas células.

As lesões orais pesquisadas por Walshet al. ${ }^{(19,28)}$ incluíram líquen plano, gengivite, pulpite e inflamação periapical, nas quais também se observou que a presença de MCs representa uma característica histológica comum dessas lesões, sendo empregada a técnica de imuno-histoquímica para pesquisa de triptase, quimase e E-seletina liberados quando da degranulação destas células. 
Batista et al. ${ }^{(29)}$ conduziram um trabalho para identificar e quantificar a presença de MCs nos diferentes estágios da doença periodontal em humanos e encontraram um número aumentado dessas células nas lesões de gengivite/periodontite crônicas. Concluiu-se que estas células podem participar tanto dos eventos destrutivos como dos mecanismos de defesa da doença periodontal, através de secreção de citocinas. Achado semelhante foi relatado por de Drazicet al., ${ }^{(30)}$ no estudo com lesões periapicais, no qual foram utilizadas as coloração de Giemsa e coloração imuno-histoquímica com o anticorpo anti-CD 117.

Além da quantificação dos MCs em fibroma de células gigantes e em hiperplasia fibrosa inflamatória, lesões de mucosa oral, Santos et al., ${ }^{(31)}$ pesquisaram o envolvimento dessas células com a fibrose e a modulação das células endoteliais e verificaram uma possível associação positiva, embora sem significância estatística. Walshet al. ${ }^{(19,28)}$ descreveram a evidente participação de MCs na inflamação crônica através da síntese e liberação continuada de fator de necrose tumoral alfa (TNF- $\alpha$ ) por estas células podendo manteramigração leucocitária e promover cronicidade em lesões inflamatórias,como no líquen plano bucal. No entanto, resultado inverso foi encontrado em uma investigação de cistos odontogênicos, em que nenhuma associação foi obtida entre MCs e inflamação. ${ }^{(32)}$

\section{CONSIDERAÇÕES FINAIS}

Diante do observado na literatura, os MCs estão distribuídos nos tecidos conjuntivos de todo o corpo humano, na presença ou ausência de processos patológicos. A participação dessas células nos processos de angiogênese e de fibrose se dá através de mediadores produzidos e lançados por eles quando estimulados pelo microambiente no qual estão localizados. Os MCs desenvolvem importantes papéis em lesões inflamatórias e no reparo, estando, provavelmente, envolvidos na patogênese das lesões inflamatórias periapicais, ulcerações aftosas recorrentes, cistos odontogênicos, entre outros. Diante do exposto, percebese a ambiguidade da atividade funcional dos MCs em diferentes contextos, fato este que contribui para estimular o espírito investigativo acerca destas células. A elucidação dos mecanismos pelos quais os MCs verdadeiramente atuam no interstício representam ainda um desafio para a comunidade científica. 


\section{REFERÊNCIAS}

1. Farahani SS, Navabazam A, Ashkevari FS. Comparison of mast cells count in oral reactive lesions. Pathol Res Pract 2010; 206: 151-5.

2. Carrera M, Pinho CB, Medrado ARP, Andrade ZA, Reis SRA. Influence of $670 \mathrm{~nm}$ lowlevel laser therapy on mast cells and vascular response of cutaneous injuries. $J$ PhotochemPhotobiol. B,Biol 2010; 98: 188-192.

3. Kumar V, Abbas AK, Fausto N. Robbins e Cotran - Patologia Bases Patológicas das Doenças. $7^{\text {a }}$ ed. Rio de Janeiro:Elsevier; 2005.

4. Galli SJ, Maurer M, Lantz CS. Mast cells as sentinels of innate immunity. CurrOpinImmunol 1999; 11: 53-9.

5. Galli SJ. Mast cells and basophils.CurrOpinHematol 2000; 7: 32-9.

6. Kalesnikoff J, Galli SJ. New developments in mast cell biology. Nat Immunol 2008; 9(11): 1215-23.

7. Levi-Schaffer F, Pe'er J. Mast cell and angiogenesis. ClinExp Allergy 2001; 31: 521-4.

8. Li CY, Baek JY. Mastocytosis and Fibrosis: Role of Cytokines. IntArch Allergy Immunol 2002; 127: 123-6.

9. Walsh LJ. Mast cells and oral inflammation.Crit Rev Oral Biol Med 2003; 14: 188-98.

10. Murata M, Hara K, Saku T. Dynamic distribution of basic fibroblast growth factor during epulis formation: an immunohistochemical study in an enhanced healing process of the gingival. J Oral Pathol Med 1997; 26: 224-32.

11. Kinet JP. The essential role of mast cells in orchestrating inflammation.Immunol Rev 2007; 217: 5-7.

12. Gordon JR, Burd PR, Galli SJ. Mast cells as a source of multifunctional cytokines.Immunol Today 1990; 11(12): 458-64.

13. Lorentz A, Schwengberg S, Sellge G, Manns MP, Bischoff SC. Human Intestinal Mast Cells Are Capable of Producing Different Cytokine Profiles: Role of IgE Receptor CrossLinking and IL-4. J Immunol2000;164: 43-8.

14. Wang H-W, Tedla N, Hunt JE, Wakefield D, McNeil HP. Mast cell accumulation and cytokine expression in the tight skin mouse model of scleroderma. ExpDermatol 2005; 14: 295-302.

15. Roberts ISD, Brenchley PEC. Mast cells: the forgotten cells of renal fibrosis. J ClinPathol 2000; 53: 858-62. 
16. Santos PPA, Freitas VS, Freitas RA, Pinto LP, Souza LB. Relação entre Mastócitos e Células T na Inflamação.OdontolClín-Cient 2010; 9(3): 215-7.

17. Gruber BL, Marchese MJ, Kew R. Angiogenic factors stimulate mast-cell migration. Blood1995; 86(7): 2488-93.

18. Riekki R, Harvima IT, Jukkola A, Risteli J, Oikarinen A. The production of collagen and the activity of mast-cell chymase increase in human skin after irradiation therapy. ExpDermatol 2004; 13: 364-71.

19. Walsh LJ, Savage NW, Ishii T, Seymour GJ.Immunopathogenesis of oral lichen planus. J Oral Pathol Med 1990; 19: 389-96.

20. Ribatti D, Vacca A, Nico B, Quondamatteo F, Ria R, Minischetti M, Marzullo A, Herken R, Roncali L, Dammacco F. Bone marrow angiogenesis and mast cell density increase simultaneously with progression of human multiple myeloma. Br J Cancer 1999; 79(3/4): 451-455.

21. Grützkau A, Krasagakes SK, Baumeister H, Schwarz C, Kögel H, Welker P, et al. Synthesis, Storage, and Release of Vascular Endothelial Growth Factor/Vascular Permeability Factor (VEGF/VPF) by Human Mast Cells: Implications for the Biological Significance of VEGF. Mol BiolCell 1998; 9: 875-84.

22. Oliveira-Neto HH, Leite AF, Costa NL, Alencar RC, Lara VS, Silva TA, et al. Decrease in mast cells in oral squamous cell carcinoma: Possible failure in the migration of these cells. Oral Oncol 2007; 43: 484-90.

23. Parizi ACG, Barbosa RL, Parizi JLS, Nai GA. Comparação entre a concentração de mastócitos em carcinomas espinocelulares da pele e da cavidade oral. AnBrasDermatol 2010; 85(6): 811-18.

24. Carrera M. Influência dos mastócitos na resposta vascular em ferimentos cutâneos submetidos à biomodulação laser. Salvador: EscolaBahiana de Medicina e SaúdePública; 2008 .

25. Miyazawa S, Hotta C, Doi N, Natori Y, Nishikawa K, Natori Y, Role of mast cells in the development of renal fibrosis: use of mast cell-deficient rats. Kidney Int 2004; 65: 2228-37.

26.Samoszuk M, Kanakubo E, Chan JK. Degranulating mast cells in fibrotic regions of human tumors and evidence that mast cell heparin interferes with the growth of tumor cells through a mechanism involving fibroblasts. BMC Cancer2005, 5: 121.

27. Natah SS, Häyrinen-Immonen R, Malmström M, Konttinen YT. Quantitative assessment of mast cell in recurrent aphthous ulcers (RAU). J Oral Pathol Med 1998; 27: 124-29.

28. Walsh LJ, Davis MF, Xu LJ, Savage NW: Relationship between mast cell degranulation and infiammation in the oral cavity. J Oral Pathol Med 1995; 24: 266-72. 
29. Batista AC, Rodini CO, Lara VS. Quantification of mast cells in different stages of human periodontal disease. Oral Dis 2005; 11: 249-54.

30. Drazic R, Sopta J, Minic AJ. Mast cells in periapical lesions: potential role in their pathogenesis. J Oral Pathol Med 2010; 39: 257-62.

31. Santos PPA, Nonaka CFW, Pinto LP, Souza LB. Immunohistochemical expression of mast cell tryptase in giant cell fibroma and inflammatory fibrous hyperplasia of the oral mucosa. Arch Oral Biol 2011; 56: 231-7.

32. Smith G, Smith AJ, Basu MK. Mast cells in human odontogenic cysts. J Oral Pathol Med 1989; 18: 274-8. 